\title{
The Future of CAiSE
}

\author{
John Krogstie, Oscar Pastor, and Barbara Pernici
}

\begin{abstract}
In this chapter an analysis of the current goals and positioning of CAiSE is provided and aims and goals for future years are discussed. First, the conference role in the Information Systems community is considered, then we focus on how the goal of maintaining the conference at top level could be achieved, in a world in which new communication venues and practices are changing established scientific practices.
\end{abstract}

\section{The CAiSE Experience and the Changing World of Publications}

Most of the editors and authors of this book have participated in many CAiSE conferences and have considered it a place where attending regularly would not only provide an excellent publication forum, but also a place where ideas could be exchanged with other researchers in the field, and, for the youngest ones, an opportunity was given to discuss new ideas with established researchers in the field.

In contrast to many other scientific disciplines, computer science considers conference publications, and as illustrated in [1] one can show formally that a few computer science conferences are equally important in terms of impact as the top journals in the field. In the last few years, a debate has started in the Computer

\footnotetext{
J. Krogstie (四)

Department of Computer and Information Science, NTNU- The Norwegian University of Science and Technology, Trondheim, Norway

e-mail: krogstie@idi.ntnu.no

O. Pastor

Centro de Investigación ProS, DSIC - Edificio 1 F, Universidad Politécnica de Valenci,

Camino de Vera S/N, Valencia 46022, Spain

B. Pernici

Politecnico di Milano, piazza Leonardo da Vinci, 32, Milan, Italy
} 
Science field on publication venues and on the role of conferences and journals in the field. It has been claimed that the focus on publications through conferences is a sign that the fields of Computer Science/Information Systems is not mature, and it is indicated also CS/IS should shift to have journals as the main publication channel, and that "Computer science should refocus the conference system on its primary purpose of bringing researchers together" [2]. We think that this is to a large degree happening already (e.g. in most countries, it is the best journals that are the most prestigious publication outlets, in particular when research evaluations and selections for positions are performed) although the set of focused workshops and conferences is very important, especially for PhD candidates to get feedback from the research community quickly enough for it to be useful towards their $\mathrm{PhD}$ thesis. It is also useful for a discipline like Information Systems and Information Systems Engineering, which deals with designed (and not natural) artifacts in interaction with human reality to have robust mechanism to build arenas for bringing people together to bring the research ahead. In particular for new research directions it is not sufficient to only read each other works in scientific journals; discussion and interaction are needed.

The paper published in CACM also lists a number of reasons for having conferences [2]:

1. To rate publications and researchers.

2. To disseminate new research results and ideas.

3. To network, gossip, and recruit.

4. To discuss controversial issues in the community.

In most fields, items 2, 3 and partly 4 are most important, although also the first is relevant as we have seen.

On the other hand, an increasing number of conferences in the Information Systems area are emerging, focusing either on general topics or on more specialized issues. The challenge therefore is not only to have a conference to provide an interesting discussion environment, but also a conference that is considered a high quality forum for exchanging ideas and meeting other researchers.

In an attempt to compare conferences in the Computer Science domain, the position of the conference in international rankings can be taken into consideration. Ranking also give criteria for such evaluations that can be considered as goals for a top level conference. For instance, in his web site, ${ }^{1}$ Osmar R. Zaïane lists the following criteria: "based on general reputation of the conference in the field, the citation of the papers published in the conference, reputation of program committee members and reputation of the review process. ... Top conferences are known for their impact history and their rigorous review process. They should be equivalent, if not superior in impact and prestige, to reputable journals".

\footnotetext{
${ }^{1}$ http://webdocs.cs.ualberta.ca/ zaiane/htmldocs/ConfRanking.html
} 
In the most comprehensive list of relevant conferences, ${ }^{2}$ published by The Computing Research and Education Association of Australasia (CORE), CAiSE is rated as a top conference, a position which we should work to keep.

As indicated above there are several indicators that can be taken into consideration in the evaluation of a conference. For community-building, one possible metric is the ratio attendants/papers. Another important point here is that the conference is relatively focused as for topics. A conference accepting papers across a large number of areas will seldom be central to a specific community. As for value for researchers, the review process is also important, with a well managed reviewing process that provides constructive feedback to the authors, both for accepted and rejected papers. One can also look at impacts (as for citations). Although not on the same level as for the top journals, the best conferences have an $\mathrm{H}$-index on the same level as the second-best journals (the numbers below are from 'Journal Impact on Publish or Parish (based on google scholar)'. The data quality might differ between different events, based on how consistently they are referenced though. Here also some SE-outlets are included (the best computing journals have an $\mathrm{H}$-index in the area of 200-300):

- EJIS-journal: 81

- IST-journal: 80

- ICSE-conference: 73

- CAiSE-conference: 66 based on conference papers (73 if you include papers in special issues)

- JAIS-journal: 66

- ICIS-conference: 58

- CAIS-journal: 57

Apart from noticeable impact as indicated above, how is CAiSE doing so far?

- Community gathering: In total the number of participants to the conference has been around 200 with around 40 papers to the main conference. Many of the those not having a role in the conference do have other roles though, e.g., in the Forum or in Workshops, thus we should work to make the conference even more attractive as a community event (e.g. have possibilities to arrange meetings for related activities, as in the case of the IFIP 8.1 Working Group, which since many years has had its business meeting at the conference). On mix of focus and development, [3] writes: "Over time, CAiSE manages to not only retain authors who are working on the established ideas of the conference, but also to attract new authors who would bring fresh ideas to the community. A comparison of the returning rating of CAiSE authors and their contributions to other conferences shows that CAiSE now retains a healthy fraction of recurring authors in order to keep the community open." Thus we can argue that there is a logical place for

\footnotetext{
${ }^{2}$ http://core.edu.au/index.php/categories/conference\%20rankings/1
} 
Fig. 1 Submission and acceptance rates

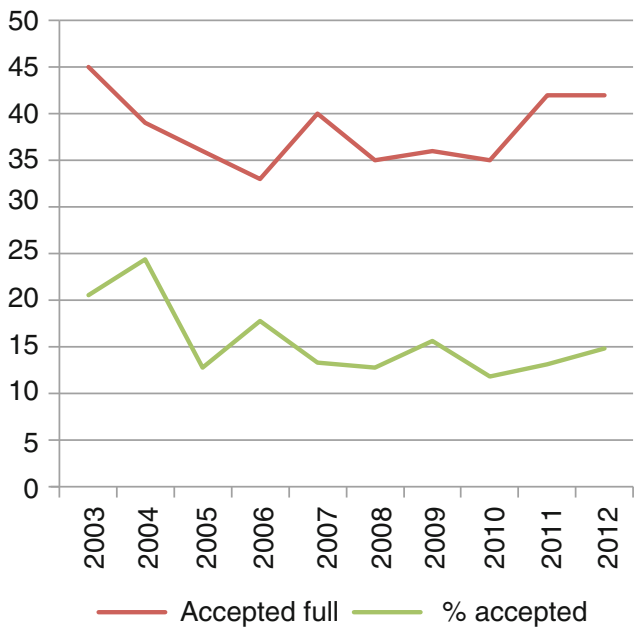

ISE, merging the more technical SE area with the more business oriented SE area as also concluded by [3].

- A top conference should have good possibilities for interaction (e.g., long discussions, special interactive sessions, doctoral consortium etc.). This should also have a positive impact for conferences and workshop that would be less prestigious as independent events: for instance, whereas the main paper sessions in CAiSE has been relatively traditional, the workshops such as EMMSAD are organized with a format where each paper is discussed over a $45 \mathrm{~min}$ slot in which the main presentation is only half of this time, thus providing more interaction. So does the forum, both types of events being able to also support the dissemination of more novel ideas. Controversial issues for the community are openly addressed in panel sessions in the main conference.

- A top conference should have a rigorous review process that ensures fair review and detailed review comments to all authors. In CAiSE for instance, three usually quite comprehensive reviews are provided from members of the international program committee. A member of the program board then looks on the reviews, and supports a discussion among the reviewers where there are differences in the ratings. Based on the reviews and further discussions, the program board and program committee members select the papers to be accepted in a program board meeting going over 2 days. Papers with novel ideas that are not thoroughly validated yet to be accepted for the main conference might be proposed for either the forum or one of the workshops.

- Impact: A top level conference typically has a 20 year + history, and it is also cited quite a lot. A top level conference would thus be expected to have a $\mathrm{H}$ index above 50. As we mentioned above, this is valid for e.g. CAiSE (and other top IS and SE conferences).

- A top level conference should have low acceptance rate $(<20)$. Figure 1 shows an illustration of the development of acceptance figures for CAiSE over the years. 
Whereas acceptance rate until 2004 was around $25 \%$, over the last years it has been below $15 \%$ (which some might argue is even a bit too low).

\section{Future Plans}

In terms of the future, the CAiSE environment provides a set of significant features that show a promising, successful future. Modern IT requirements recognize more than ever the importance of Engineering Information Systems correctly. It is not just a matter of "Software". Information Systems design and implementation cover all the facets of our society, and new challenges appear continuously. CAiSE is intended to be the natural forum where past, present and future of Information Systems Engineering should be properly discussed and explored.

While keeping a top quality level - including both an academic perspective and the practical applications - is already a must for CAiSE, it is also remarkable the friendly atmosphere that has been created during this 25-years old trip. When a sound and rigorous scientific environment is linked to a friendly and pleasant working environment, centered around a relatively well-defined topic area the working context as a whole becomes much richer. This is happening year after year with CAiSE, and this is part of the conference idiosyncrasy that every organizer is committed to preserve and reinforce.

Incorporating young, brilliant researchers to the community is another "must" for the CAiSE community. It is well recognized how important it is to balance the experience of seniors with the enthusiasm of juniors. The quality required by the Scientific Committees of the conference requires also to open the community to different countries. From its initially European conception, the very next future will continue broadening the CAiSE influence to the rest of the world, reinforcing continuously the already relevant participation of scientists from America, Asia, Australia, and Africa.

There are many other tasks to accomplish. Improving and adapting the conference format with the new times, using extensively the capabilities of social networks, exploring advance channels of publication of papers, providing a journalbased style for the CAiSE audience... Many new ideas to explore to show to the community the sound compromise of fitting the requirements of our modern IToriented society. Our CAiSE community has a real potential to make all these goals come true, through the accumulated amount of people and knowledge that is ready to explore new ways being fully respectful with all the experience accumulated in the past. This is by far the most important legacy of these 25 years of history. We have a very strong basis to face new challenges.

Summarizing, from the hard and brilliant work that so many people have done in this 25 exciting years, CAiSE has the exciting challenge of becoming the most top-ranked international conference of Information Systems Engineering. We are all committed to this task, and you are all invited to share the CAiSE adventure with us for - at the very least - the next 25 years. 


\section{References}

1. Pham, M.C., Klamma, R., and Jarke, M. (2011) Development of computer science disciplines: a social network analysis approach. Social Netw. Analys. Mining, 1(4):321-340.

2. Fortnow L. (2011) CACM Viewpoint: Time for computer science to grow up, Communications of the ACM, Vol. 52 No. 8, Pages 33-35

3. Jarke, M., Pham, M.C., and Klamma, R. (2013) Evolution of the CAiSE Author Community: A Social Network Analysis. This book, Chapter 2, Springer. 